\title{
Article \\ A Convex Dynamic Approach for Globally Optimal Profit in Supply Chains
}

\author{
Mojtaba Azizian, Mohammad Mehdi Sepehri * and Mohammad Ali Rastegar (D)
}

check for updates

Citation: Azizian, M.; Sepehri, M.M.; Rastegar, M.A. A Convex Dynamic Approach for Globally Optimal Profit in Supply Chains. Mathematics 2022, 10, 498. https://doi.org/10.3390/ math10030498

Academic Editors: Armin

Fügenschuh and Frank Werner

Received: 5 December 2021

Accepted: 25 January 2022

Published: 3 February 2022

Publisher's Note: MDPI stays neutral with regard to jurisdictional claims in published maps and institutional affiliations.

Copyright: () 2022 by the authors. Licensee MDPI, Basel, Switzerland. This article is an open access article distributed under the terms and conditions of the Creative Commons Attribution (CC BY) license (https:// creativecommons.org/licenses/by/ $4.0 /)$.

\author{
Faculty of Industrial and Systems Engineering, Tarbiat Modares University, Tehran 1411713116, Iran; \\ m.azizian@modares.ac.ir (M.A.); ma_rastegar@modares.ac.ir (M.A.R.) \\ * Correspondence: mehdi.sepehri@modares.ac.ir
}

\begin{abstract}
Supply chain finance aims to coordinate multiple stakeholders to maximize the flow of cash and internal and external funding along the supply chain, as shown in prior research. From a regulatory standpoint, the goal of this paper is to maximize the profitability of an entire supply chain. As a result, a constrained finite time Linear Quadratic Regulation (LQR) approach is provided for determining an entity's optimal profit state in a supply chain. The framework is represented by discrete-time linear dynamical equations for each entity in the supply chain network, taking state and input variables into account. The problem is formulated in terms of a convex quadratic programming optimization for which several numerically efficient algorithms are readily available. In order to validate the approach, it was tested on two topologies. The first topology is a fully connected supply chain with six nodes; the second is a simple topology based on the Iranian pharmaceutical supply chain. The results indicate that the proposed approach successfully planned production and financing decisions within the simulated supply chain and obtained globally optimal profit for all supply chain stakeholders.
\end{abstract}

Keywords: financial supply chain management; simulation; optimization; optimal control; linear quadratic regulation; linear dynamical equations

\section{Introduction}

A supply chain (SC) is a collection of organizations' operations that are linked and interact, both directly and indirectly, to transform inputs into outputs that are provided to the ultimate customer [1]. The field of supply chain management concerns itself with the collaboration and coordination of several stakeholders to optimize the flow of goods, information, and finance along the entire SC [2]. The financial supply chain differs from the physical supply chain in that it deals with the flow of cash rather than commodities and is in the opposite direction, according to Popa (2013) [3]. Financial flows along the SC form an essential part of the continuum of the business operation [4,5], and despite the potential of supply chain management (SCM), relatively few companies utilize interorganizational network settings to drive financial performance in a collaborative way [6].

Caldentey and Chen [7] believed that planning, managing, and controlling financial flows along SCs positively affect SC profitability. In recent decades, the frameworks of financial supply chain management (FSCM) and supply chain finance (SCF) have advanced dramatically.

Supply chain finance strives to coordinate several stakeholders in order to optimize the flow of cash and internal and external funding along the supply chain. This paper aims to maximize the profitability of the entire whole supply chain from a regulatory point of view.

The rest of the paper is organized as follows: In Section 2, we provide a review of related literature. In Section 3, a discrete-time linear dynamical model of the entities within the supply chain network is proposed. In Section 4, a constrained finite-horizon LQR 
problem is presented to demonstrate how decision variables are optimally obtained to reach the specified goals with given priorities implemented in the cost function. In Section 5 , the results of numerical simulation which validate our results are shown. A brief conclusion is rendered in Section 6.

\section{Literature Review}

In recent years, academics have paid increased attention to the issue of integration and coordination among SCF members. FSCM is commonly referred to in the literature as programs developed to focus on supplier-buyer relationships and manage the financial flow throughout a SC; a flow that is in the opposite direction of physical and informational flows [3,8,9]. SCF includes a range of financial instruments implemented to finance members of a supply chain and is generally considered a subset of FSCM [10].

As Hofmann et al. [11] stated, traditionally, the majority of SC actors are preoccupied with their own concerns and objectives, failing to coordinate financially with their SC partners. The lack of a shared vision among SC partners is a big impediment for SCF [4]. FSCM thus requires collaboration beyond the firm's borders with service providers (such as banks), suppliers, and customers [8]. The working capital state of a firm is affected by the firm's operational environment and its SC dynamics. Monto et al. [12] stated that with efficient working capital management, a company could reduce the need for finance, free up cash, increase profitability, improve liquidity, increase the efficiency of operations, and decrease (financing) costs. However, Kouvelis and Zhao [13] pointed out that to achieve a successful FSCM plan and its advantages, active working capital coordination among SC parties is needed.

There are two widely used types of financing a firm can accept: Bank Credit Financing (BCF) and Trade Credit Financing (TCF) [14,15]. The former refers to short-term financing provided by an external financier regarding the scope of a SC. The latter is used when short-term loans are acquired by extending payment terms between exchange partners within the SC. It is harder for small and medium enterprises (SMEs) to receive financing from banks due to their high levels of credit risk; thus, trade credit is considered as an alternative for financing SMEs. TCF has been proven to be more effective than BCF only when the production costs are relatively low [16].

The measure of the cash conversion cycle (CCC) was introduced by Richards and Laughlin [17] to evaluate and control a firm's working capital management efficiency. CCC is composed of the cycle time of inventories (DIO), cycle time of accounts receivable (DRO), and the cycle time of accounts payable (DPO). Deloof [18] suggested that shortening the CCC of a firm is positively correlated with its profitability. According to Hofmann and Kotzab [19], improving a firm's CCC (extending payables period and shortening receivables period) might be achieved at the expense of its SC partners; therefore, they proposed a measure named collaborative cash conversion cycle (CCCC), which is the sum of CCC of all exchange partners.

Numerous techniques have been applied to optimize the working capital within the SC [19-24]. There are numerous methods to model SC management problems; some of the most popular include linear programming [25], non-linear programming, multi-objective programming [26], and stochastic programming [26] to account for uncertainty [27]. These techniques have been demonstrated to be the most effective solutions for solving quantitative decision-making difficulties while still providing an optimal solution. Furthermore, constraints handling is straightforward and limited resources can be allocated based on the criteria formulated in the given cost function.

Linear programming is a popular approach in different areas of SC optimization. It is an efficient tool to model and analyze investment, production planning, and scheduling [28,29]. Sahay and Ierapetritou [30] introduced an optimization model based on linear programming to manage the orders among different entities inside a SC. Recursive discretetime equations are used to capture the dynamic nature of the inventory levels. Park and Kim [31] proposed a framework to study operational planning of global SCs by formulating 
a linear programming problem considering the production lot sizes, order quantity, and ordering decisions of distribution centers (DCs). Kirilmaz and Erol [32] presented a five-level approach based on a linear programming model to build a robust SC in terms of supply-side risk criteria, such as disruption or delay in supplier production. Non-linear programming has the capability to model more detailed aspects of the SCs, as well as non-linear constraints. Tabrizi and Razmi [33] proposed the mixed-integer non-linear fuzzy approach to model the SC network by considering uncertainty in the supply, demand, and processing sides. In order to account for demand unpredictability, Applequist et al. [34] solved a mixed-integer non-linear programming problem in which the risk premium is offered as a metric to explicitly incorporate economic risk into the model. Stochastic programming is another optimization framework that is specifically developed to solve problems involving uncertainty. Carneiro et al. [35] applied a stochastic programming model to maximize the expected net present value. Sodhi [36] employed stochastic modeling in the tactical SC planning to determine future shipments to customers over the pre-defined horizon. Klibi and Martel [37] proposed several stochastic programming approaches to design resilient supply networks in the location-transportation context. In some cases, there may be contradictory objectives to address in SC management optimization models. Trisna et al. [26] conducted a literature review in the area of multi-objective programming for SC management. Among these studies, D'Amore and Bezzo [38] combined this idea with other programming techniques. They proposed a general multi-objective mixed-integer linear programming framework in order to determine the strategic planning decisions and design of a SC in a bioethanol context.

Although using optimization for modeling SC management and risk mitigation is common, most of these methods do not consider the dynamical nature of the system under study $[32,38,39]$. Some researchers have focused on how to consider the dynamical behaviors of entities in the model. Petri Nets are mathematical modeling frameworks with a formal graphical structure for analyzing concurrent distributed systems. Kabir and Papadopoulos [40] monitored dynamical changes of each node in SC systems. Timed Petri Net is one of the main extensions used for conducting risk analysis and real-time control of SC networks (Tuncel and Apan [41]). The colored Petri Nets are another extension capable of describing information classification based on defining various colorful tags. Liu et al. [42] implemented this method to classify information referring to environment, product quality, and processing data for a perishable SC network in which time is a crucial factor.

Regarding the topology of the SC understudy, Nair and Vidal [43] pointed out that the topology of a supply network has a significant impact on its risk and resilience. Different types of networks have been investigated in the literature. The choice of topology is related to the purpose of the study. Two-level SCs are popular among game-theoretical approaches to study buyer-supplier relationships to determine decisions about wholesaling price, order quantity, credit term, and financing rates [44-47]. Complex topologies are examined to investigate SC finance design [48].

The study of default propagation within the SC is another research stream that is utilized by complex SCs. Zhao et al. [49] took advantage of a complex network to investigate credit risk diffusion within a SC. Some approaches considered a dynamic network topology to monitor the effect of different strategies implemented by SC entities on the network topology [50,51].

While optimization models could solve different SC-related problems, simulation is an efficient computer-based tool for evaluating behaviors of various entities in a SC network, from the conceptual development phase to SC usage in real-life scenarios $[27,52,53]$. Simulation techniques are divided into four categories: Wu et al. [54] conducted agent-based simulation to study stock-out effects in the two-stage SC. Elleuch et al. [55] applied discreteevent simulation to experiment with risk impacts and mitigation policies in a pharmacy. System Dynamic was proposed by Forrester [56] to model highly complex systems subject to great levels of uncertainty. For example, a System Dynamic model was introduced to 
analyze the behavior of the post-seismic SC through simulation [57]. Liew and Lee [58] performed a Monte Carlo simulation to quantify marine/offshore industry risks. The same approach for testing the resilience of SC management models toward risk is adopted by Olson and $\mathrm{Wu}[59]$.

An optimization model is derived as a modeling framework in the optimization methodologies for SC management. Optimization problems, in general, have a static nature, and the performance of the proposed optimization models is studied under specific simulation settings. Furthermore, there is no guarantee for global optimality [60]. In this paper, we propose a novel approach toward modeling the entities in the SC. The financial state of each agent is modeled by a system of discrete-time linear dynamical equations by considering the incoming order frequency of each entity, the daily production amount, short-term financing, and debt repayments to upstream entities. This model is implemented on two topologies: the first is a fully connected SC with six nodes and the second is a simple topology of the Iranian pharmaceutical SC.

The practical constraints in the SC are captured by introducing a set of inequalities. For the purpose of gaining profit for the SC members, a constrained finite-horizon (LQR) problem is formulated [61]. We will show this problem can be transformed to quadratic programming with convex settings. Hence, the optimal global solution for managing the production level of entities and financial flow in the SC network is obtained in a centralized framework.

\section{Model Description}

Since SCF variables such as available working capital, inventory value, debt to other entities, and debt to the bank have memory (i.e., their future value is a function of their current value), modeling them by a dynamical system is appropriate. In addition, financial information and financial decisions are usually updated periodically. As a result, the state variables, control inputs, and SC network parameters listed in Tables 1-3 are enough to represent each entity in the SC network using a set of discrete-time linear dynamical equations. The state variables are the variables sufficient to implement the total behavior of each entity and are recursively updated each day based on the previous state and the current input signals. The input signals are the decision variables that manipulate the corresponding states.

Table 1. State variables.

\begin{tabular}{cc}
\hline Notation & Description \\
\hline$I_{i}(k)$ & Available working capital of entity $i$ at day $k$ \\
\hline$Q_{i}(k)$ & Profit value of entity $i$ until day $k$ \\
\hline$M_{i}(k)$ & Inventory value of entity $i$ at day $k$ \\
\hline$D_{i j}(k)$ & Debt value of entity $i$ to entity $j$ at day $k$ \\
\hline$D_{i b}(k)$ & Debt value of entity $i$ to the bank at day $k$ \\
\hline
\end{tabular}

Table 2. Input Signals.

\begin{tabular}{cc}
\hline Notation & Description \\
\hline$N_{i}(k)$ & Production value of entity $i$ at day $k$ \\
\hline$L_{i}(k)$ & Short-term financing received by entity $i$ at day $k$ \\
\hline
\end{tabular}


Table 3. External input variables.

\begin{tabular}{cc}
\hline Notation & Description \\
\hline$O_{i}(k)$ & Value of shipped product to downstream entities by entity $i$ at day $k$ \\
\hline$R_{i j}(k)$ & Account receivable from order issued by entity $i$ to entity $j$ at day $k$ \\
\hline$P_{i j}\left(k, k^{\prime}\right)$ & Net cash obtained at day $k$ by order issued from entity $i$ to entity $j$ at day $k^{\prime}$ \\
\hline
\end{tabular}

In Table 1, state variables describe the amount of available working capital and profit value, inventory level, and debt value of each entity.

The production and payment value of each member and short-term financing received by each entity are considered input signals and are shown in Table 2.

The external inputs necessary to model the physical and order flow among entities in the SC network are displayed in Table 3.

The other parameters considered in the model and the entities within a SC network are presented in Table 4.

Table 4. Network parameters.

\begin{tabular}{cl}
\hline Notation & Description \\
\hline$C_{c i}$ & Daily fixed cost for entity $i$ \\
$C_{v i}$ & Variable cost per unit value of production for entity $i$ \\
$R$ & Yearly interest rate related to the payment extension term \\
$P p_{i}$ & Yearly cost of capital related to short-term financing received by entity $i$ from the bank \\
$N_{u}(i)$ & The set of upstream entities of entity $i$ \\
$N_{d}(i)$ & The set of downstream entities of entity $i$ \\
$T$ & Payment term of short-term financing in the model \\
$T_{p}$ & Purchase period of the orders between entities \\
$N$ & Total number of entities in the SC network \\
$n_{c}$ & Total number of connected entities \\
$n_{u i}$ & Total number of upstream entities of entity $i$ \\
$\widetilde{m}_{i}$ & Upper limit of inventory value for entity $i$ \\
$\widetilde{i}_{i}$ & Upper limit of working capital for entity $i$ \\
$\widetilde{n}_{i}$ & Upper limit of production for entity $i$ \\
$\tilde{n}_{i}$ & Lower limit of production for entity $i$ \\
$\widetilde{d}_{i j}$ & Upper limit of entity $i$ debt to entity $j$ \\
$\widetilde{l}_{i}$ & Upper limit of short-term financing for entity $i$ \\
$\widetilde{p}_{i}$ & Upper limit of payment value for entity $i$ \\
\hline
\end{tabular}

\section{Mathematical Formulation}

In this section, the dynamical behavior of each SC entity's working capital, inventory, and debt value is formulated with a discrete-time linear dynamical model.

Equation (1) calculates inventory value at the beginning of each day, $M_{i}(k+1)$, by considering the inventory value the day before, $M_{i}(k)$, and changes to the inventory value due to production and shipment of goods, $N_{i}(k)-O_{i}(k)$, on the previous day.

$$
M_{i}(k+1)=M_{i}(k)+N_{i}(k)-O_{i}(k) \quad k=1,2,3, \ldots
$$

Equation (2) calculates $i$-th entity working capital at the beginning of day $k$ by reducing the fixed and variable costs, planned payments to the upstream entities, and the bank from the previous day working capital of entity $i$.

$$
I_{i}(k+1)=I_{i}(k)-C_{c i}-C_{v i} N_{i}(k)-\sum_{j \in N_{u}(j)} \sum_{k^{\prime}} P_{i j}\left(k, k^{\prime}\right)-\left(1+p p_{i} \times \frac{T}{365}\right) L_{i}(k-T)+\sum_{j \in N_{d}(j)} \sum_{k^{\prime}} P_{i j}\left(k, k^{\prime}\right)+L_{i}(k)
$$

Working capital is also increased by received short-term borrowing and payments from downstream businesses the day before. Short-term financing has a $T$-day payment duration in the proposed paradigm. Hence, the value of the short-term financing is compounded 
for a T-day period. Equations (3) and (4) keep track of the debt of entity $i$ to its upstream entities and the bank, respectively.

$$
\begin{gathered}
D_{i j}(k+1)=D_{i j}(k)\left(1+\frac{r}{365}\right)+R_{i j}(k)-\sum_{k^{\prime}} P_{i j}\left(k, k^{\prime}\right) \\
D_{i b}(k+1)=D_{i b}(k)+L_{i}(k)-\left(1+p p_{i} \times \frac{T}{365}\right) L_{i}(k-T) \\
P_{i j}\left(k, k^{\prime}\right)=\left(1+\frac{r}{365}\right) R_{i j}\left(k^{\prime}\right)^{k-k^{\prime}}
\end{gathered}
$$

In Equation (5), the debt of each entity on the previous day is compounded daily, with new debts and repayments of the previous accounts taken into account to calculate $i$-th entity's debt at the beginning of day $k$. Equation (6) has the same structure; only the compounding occurs to take the $T$-day payment term to the bank into account.

The model of working capital state can be modified to incorporate the profit value of each entity in the SC. Therefore, the profit value is obtained from Equation (2) by omitting the effects of received short-term financing.

The obtained profit equation until the $k$-th day has resulted from the profit achieved until the prior day by reducing fixed and variable costs of each entity, payments to the upstream entities, and payments to the bank due to the received short-term financing. Received payments from downstream entities increase the profit value of each entity in the SC network. Recursively computing the profit at each day from the initial planning day yields the following equation for formulating the total profit value of each entity at each planning period.

$$
Q_{i}(k+1)=Q_{i}(k)-C_{c i}-C_{v i} N_{i}(k)-\left(p p_{i} \times \frac{T}{365}\right) L_{i}(k-T)-\sum_{j \in N_{u}(j)} R_{i j}(k)+\sum_{j \in N_{d}(j)} R_{i j}(k)
$$

The suggested model's state and input variables must adhere to certain limitations. Equations (7)-(13) formulate these constraints:

$$
\begin{gathered}
n_{i} \leq N_{i}(k) \leq \widetilde{n}_{i} \\
0 \leq M_{i}(k) \leq \widetilde{m}_{i} \\
0 \leq I_{i}(k) \leq \widetilde{i}_{i} \\
0 \leq D_{i j}(k) \leq \widetilde{d}_{i j} \\
0 \leq D_{i b}(k) \leq \widetilde{i_{i}} \\
0 \leq L_{i}(k) \leq \widetilde{l}_{i} \\
0 \leq P_{i j}(k) \leq \widetilde{p}_{i}
\end{gathered}
$$

Equation (7) shows that each entity must plan its production within a certain range to avoid high production fluctuation. The inventory level of an entity can never be negative, and it is also bounded Equation (8). Similarly, entities' working capital, debt to upstream agents, short-term financing, and payment amounts take non-negative values and have upper bounds (Equations (9)-(13)). In addition, the indebtedness of an entity to the bank takes non-negative values because we do not consider risk-free investment of the nodes in our model. The upper bound for Equations (10)-(12) is considered the initial working capital of entities. 


\section{Solution Strategy}

Consider the following linear time-invariant dynamical model:

$$
\boldsymbol{x}(k+1)=\boldsymbol{A} \boldsymbol{x}(k)+\boldsymbol{B} \boldsymbol{u}(k)
$$

where $\boldsymbol{x}(k) \in R^{n}$ and $\boldsymbol{u}(k) \in R^{m}$ are the state and input vectors, respectively, and the matrices $\boldsymbol{A} \in R^{n \times n}$ and $\boldsymbol{B} \in R^{m \times n}$ denote the state and input matrices, respectively, which operate on the present values of the state and input vectors to make the best linear estimation for the values of the state vector for the next period, as shown in Equation (14). Additionally, the pair $\boldsymbol{A}, \boldsymbol{B}$ are controllable, which means the vector of input variables, $\boldsymbol{u}(k)$, can steer a system in a given model, from any initial state vector $x(0)$ to any arbitrary state vector $x(k)$ infinite horizon [62]. To optimally minimize the states and input of Equation (14), the following constrained finite-time LQR problem is formulated.

$$
\begin{gathered}
\min _{u(0), \ldots, u(N-1)} \boldsymbol{x}(N)^{T} \boldsymbol{P} \boldsymbol{x}(N)+\sum_{k=0}^{N-1} \boldsymbol{x}(k)^{T} \boldsymbol{Q} \boldsymbol{x}(k)+\boldsymbol{u}(k)^{T} \boldsymbol{R} \boldsymbol{u}(k) \\
\quad \begin{array}{c}
\text { Subject to } \\
\boldsymbol{x}(k+1)=\boldsymbol{A} \boldsymbol{x}(k)+\boldsymbol{B} \boldsymbol{u}(k), \quad k=0,1, \ldots, N-1 \\
(\boldsymbol{x}(k), \boldsymbol{u}(k)) \in D, \quad k=0,1, \ldots, N-1
\end{array}
\end{gathered}
$$

where $Q$ is the positive semi-definite state penalty matrix, $R$ is the positive definite input penalty matrix, and $\boldsymbol{P}$ denotes the final state positive semi-definite penalty matrix [63].

In order to implement the designer's priorities toward reaching the optimal solution, these matrices should be chosen in diagonal form. The values of the diagonal elements demonstrate the relative weight that the optimizer considers in minimizing the total cost function. The state and input variables are assumed to be constrained to the closed set $(D)$ and have zero points in the interior. It is straightforward to show that the problem formulated in Equation (15) could yield to the convex QP with the globally optimal solution [64].

\section{Problem Formulation}

This section seeks to determine the optimal financial flow and production level for the SC's entities in order to maximize profit. As a result, we will illustrate how we may use Equation (14) to represent the complete SC network and formulate the appropriate constrained finite-time $\mathrm{LQR}$ to meet $\mathrm{SC}^{\prime}$ 's intended goal in the centralized view. According to this approach, part of the entity's behavior is considered collectively in terms of joint input signals [65]. Thus, the connected network in the SC obtains the optimal joint input variables and the optimal individual control variables for each entity. To model the SC with Equation (14), let us define $x(k) \in R^{3 n+n_{c}}$ and $u(k) \in R^{2 n+n_{c}}$ vectors as the augmented state and input vectors as follows:

$$
\begin{gathered}
x(k)=\left(\bar{M}(k), \bar{D}_{i b}(k), \bar{D}_{i j}(k), \bar{e}_{Q}(k)\right)^{T} \\
\boldsymbol{u}(k)=\left(\bar{N}(k), \bar{L}(k), \bar{P}_{i j}(k)\right)^{T}
\end{gathered}
$$

in which the state variables $\bar{M}(k), \bar{D}_{i b}(k), \bar{D}_{i j}(k)$, and $\bar{e}_{Q}(k)$ collect the state variables of entities at each day $k$ as follows:

$$
\begin{gathered}
\bar{M}(k)\left(M_{1}(k), M_{2}(k), \ldots, M_{n}(k)\right)^{T} \\
\bar{D}_{i b}(k)\left(D_{1 b}(k), D_{2 b}(k), \ldots, D_{n b}(k)\right)^{T} \\
\bar{D}_{i j}(k)\left(D_{i j}(k)\right)^{T} i \in n, j \in N_{u}(i) \\
\bar{e}_{Q i}(k)\left(e_{Q 1}(k), e_{Q 2}(k), \ldots, e_{Q n}(k)\right)
\end{gathered}
$$


where $e_{Q i}(k)$ is the difference term between the profit value and the pre-defined profit level for $i$-th entity $\bar{e}_{Q i}(k) Q_{i}(k)-\widetilde{Q}_{i}$ until the $k$-th day. In addition, $\bar{N}(k), \bar{L}(k)$, and $\bar{P}_{i j}(k)$ collect the input signals of entities similar to the structure presented in Equation (18) as follows:

$$
\begin{gathered}
\bar{N}(k)\left(N_{1}(k), N_{2}(k), \ldots, N_{n}(k)\right)^{T} \\
\bar{L}(k)\left(L_{1}(k), L_{2}(k), \ldots, L_{n}(k)\right)^{T} \\
\bar{P}_{i j}(k)\left(P_{i j}(k)\right)^{T} i \in n, j \in N_{u}(i)
\end{gathered}
$$

By considering collected state and input vectors as in Equation (16), the linear timeinvariant dynamical model for the whole SC is obtained with an additional known parameter $d(k)$ as $\boldsymbol{x}(k+1)=\boldsymbol{A} \boldsymbol{x}(k)+\boldsymbol{B} \boldsymbol{u}(k)+d(k)$, where $\boldsymbol{A}$ and $\boldsymbol{B}$ are the state and input matrices with sufficient dimensions, respectively, and $d(k)$ gathers the known time-varying and fixed parameters of the network. In practical financial SC problems, the amount of $d(k)$ is sufficiently small for all days, such that it cannot cause infeasibility [66].

Now, by having the linear time-invariant model of the SC at hand, we will demonstrate how we can formulate the centralized constrained finite-time LQR for the SC network. Formulating the desired goals for each entity with the corresponding quadratic cost functions leads to Equation (15).

The cost function should implement the design goals of the SC. Therefore, to minimize the debt values, short-term financing received, and the inventory level among the SC members in the planning horizon, the following cost function is considered:

$$
V_{i}(k)=g_{D_{i j}} D_{i j}^{2}(k)+g_{D_{i b}} D_{i b}^{2}(k)+g_{M_{i}} M_{i}^{2}(k)+g_{L_{i}} L_{i}^{2}(k)
$$

The terms $g_{D_{i j}}, g_{D_{i b}}, g_{M_{i}}$ and $g_{L_{i}}$ are positive weights corresponding to the goal of minimizing the debt of each entity to upstream members, the debt of each entity to the bank, the inventory level, and the amount of financing received, respectively. Furthermore, we must add an extra term $g_{N_{i}} N_{i}^{2}(k)$ with relatively little amounts for $g_{N_{i}}$ in comparison with other gains, only to make the corresponding $\boldsymbol{R}$ matrix in Equation (15) be positive definite and ensure stability of the states as the following:

$$
V_{s i}(k)=V_{i}(k)+g_{N_{i}} N_{i}^{2}(k)
$$

The resulted constrained finite-horizon LQR setting for $i$-th entity is as follows:

$$
\begin{aligned}
& \min _{L_{i}(0), \ldots, L_{i}(N-1)} \sum_{k=0}^{N-1} V_{s i}(k)+V_{f i}(N) \\
& N_{i}(0), \ldots, N_{i}(N-1) \\
& P_{i j}(0), \ldots, P_{i j}(N-1) \\
& j \in N_{u}(i)
\end{aligned}
$$

Subject to:

Equations (1) and (3) to Equation (13).

where $V_{s i}(k)$ is the stage cost that contains state and input variables of the model and is computed each day. $V_{f i}(N)$ corresponds to the final state cost function to consider profitability at the end of the horizon for each entity and is defined as follows:

$$
V_{f i}(N)=g_{D_{i j}} D_{i j}^{2}(N)+g_{D_{i b}} D_{i b}^{2}(N)+g_{M_{i}} M_{i}^{2}(N)+g_{Q_{i}}\left(Q_{i}(N)-\widetilde{Q}_{i}\right)^{2}
$$

By considering state and input vectors as in Equation (16), the state penalty matrix $Q:=\operatorname{diag}\left(g_{M i}, g_{D i b}, g_{D i j}, 0\right)$ and the input matrix penalty $\boldsymbol{R}:=\operatorname{diag}\left(g_{N i}, g_{L i}\right)$ result. Furthermore, $\boldsymbol{P}:=\operatorname{diag}\left(g_{M i}, g_{D i b}, g_{D i j}, g_{Q i}\right)$ is equal to the final state penalty matrix in Equation (15), with "diag" denoting the diagonal matrix for corresponding cost coefficients. To acquire the input signals of entities in the SC network optimally using a centralized 
view, let us describe the network's total cost function as an accumulation of the separately allocated costs for each entity as follows:

$$
\begin{gathered}
\min _{L_{i}(0), \ldots, L_{i}(N-1)} \sum_{i=0}^{n} \sum_{k=0}^{N-1} V_{s i}(k)+V_{f i}(N) \\
N_{i}(0), \ldots, N_{i}(N-1) \\
P_{i j}(0), \ldots, P_{i j}(N-1) \\
j \in N_{u}(i) \\
i \in n
\end{gathered}
$$

Subject to:

Equations (1) and (3) to Equation (13).

To solve the resulting optimization problem formulated for the centralized SC with batch approach, we define $X=(x(0), x(2), \ldots, x(N)) \in R^{(N+1) \times\left(2 n+n_{c}\right)}$ as the accumulated state vector and the accumulated decision variables vector as $U=(\boldsymbol{u}(0), \boldsymbol{u}(2), \ldots, \boldsymbol{u}(N-1)) \in$ $R^{(N) \times\left(2 n+n_{c}\right)}$ during the planning horizon $(N)$, respectively. The state and input penalty matrices are positive semi-definite and positive definite by construction, respectively. By writing dynamical Equations (1)-(5) that appeared in the constraints set of Equation (23) recursively into the form $X=\bar{X}(0)+G U$ and substituting it in the problem defined in Equation (18), it yields to the following general inequality constrained QP [63]:

$$
\min _{U} U^{T} P_{q p} U+2 Q_{q p} U+r_{q p} \text { Subject to }: A U \leq b
$$

where $\bar{X}(0)$ is the vector of initial state values and the fixed parameters related to the model and orders. Based on the facts provided in this section for the problem formulated with Equation (23), it implies that $P_{q p}$ is a positive definite matrix [63]. If any $U$ satisfies the constraint set of problem Equation (24), the problem is feasible and the convexity yields the optimal solution.

\section{Simulation}

In order to demonstrate the validity of our proposed method, we consider two scenarios in which the SC members try to reach their pre-defined profit level at the end of the planning horizon. Topology 1 is a fully connected SC with six nodes and pre-defined values for parameters. Topology 2 is based on the Iranian pharmaceutical SC, with financial values extracted from the financial statement.

Among the several methodologies for solving quadratic programming, active-set methods and interior-point methods are the most frequently utilized. However, interiorpoint approaches are preferred due to their scalability when the number of constraints and decision variables is not small [67].

The problem formulation and optimization modeling were carried out in the MATLAB optimization toolbox with its quadratic programming solver (quadprog), which uses the interior-point algorithm. In both cases, the solver converged to the optimal global solution after a few iterations since the matrix $\boldsymbol{P}$ was positive-definite which rendered the problem convex. The simulations were performed on a server with two processors, a $2.4 \mathrm{GHz} \mathrm{CPU}$, and 32 GB of RAM.

\subsection{Topology 1}

A three-level SC network with two entities at each level is considered for the simulation. The SC topology is depicted in Figure 1. Each entity in the SC is considered as a node, and the connections among nodes in which the downstream nodes only send orders to their upstream neighbors are demonstrated with arrows. The orders differ in amount (financial value of the order) and frequency. 


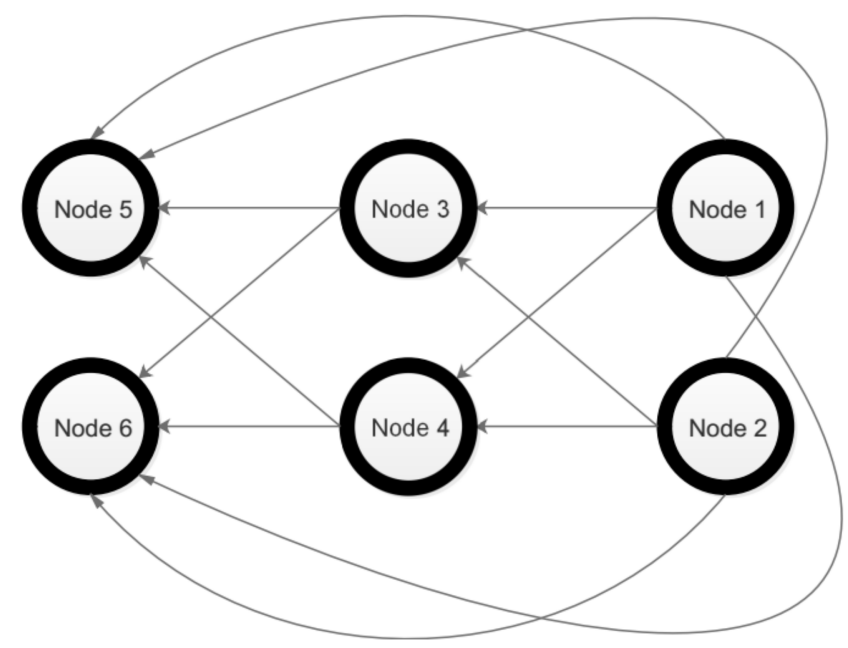

Figure 1. Topology 1 of a SC.

Table 5 summarizes the amount and frequency of orders sent to the suppliers by each node in tuples of the form (amount, frequency).

Table 5. Ordering behavior of nodes in Topology 1.

\begin{tabular}{ccccccc}
\hline From/To & Node $\mathbf{1}$ & Node $\mathbf{2}$ & Node 3 & Node 4 & Node 5 & Node 6 \\
\hline Node 1 & - & - & $(150,10)$ & $(100,5)$ & $(45,5)$ & $(195,20)$ \\
\hline Node 2 & - & - & $(235,12)$ & $(50,6)$ & $(135,14)$ & $(145,10)$ \\
\hline Node 3 & - & - & - & - & $(45,8)$ & $(95,5)$ \\
\hline Node 4 & - & - & - & - & $(31,8)$ & $(47,5)$ \\
\hline
\end{tabular}

Orders received (by Nodes 1 and 2) and sent (by Nodes 5 and 6) to the outside of the network by nodes in the output and input layer are described in Table 6.

Table 6. Orders related to the outside of the network in Topology 1.

\begin{tabular}{cc}
\hline Orders Description & (Amount, Frequency) \\
\hline Orders received by Node 1 & $(360,5)$ \\
Orders received by Node 2 & $(325,5)$ \\
Orders sent by Node 5 & $(220,20)$ \\
Orders sent by Node 6 & $(410,10)$ \\
\hline
\end{tabular}

The initial inventory value and fixed-parameter values that are specific to each entity are presented in Table 7. Entities plan their daily production to prepare for the complete delivery of downstream orders. To avoid inconsistency, upper and lower limits are defined for production. Fixed and variable costs are set to leave each entity a profit margin.

Table 7. Specific parameters of entities in Topology 1.

\begin{tabular}{cccccc}
\hline From/To & $\boldsymbol{M}_{\boldsymbol{i}}(\boldsymbol{O})$ & $\boldsymbol{P} \boldsymbol{p}_{\boldsymbol{i}}(\mathbf{\%})$ & $\left(\tilde{\boldsymbol{n}}_{\boldsymbol{i}}, \mathbf{n}_{\boldsymbol{i}}\right)$ & $\boldsymbol{C}_{\boldsymbol{c} \boldsymbol{i}}$ & $\boldsymbol{C}_{\boldsymbol{v} \boldsymbol{i}}$ \\
\hline Node 1 & 50 & 22 & $(60,73)$ & 0.4 & 0.31 \\
\hline Node 2 & 280 & 21 & $(55,66)$ & 0.4 & 0.15 \\
\hline Node 3 & 120 & 24 & $(25,35)$ & 0.4 & 0.22 \\
\hline Node 4 & 130 & 24 & $(29,36)$ & 0.4 & 0.43 \\
\hline Node 5 & 80 & 26 & $(23,35)$ & 0.5 & 0.32 \\
\hline Node 6 & 90 & 26 & $(53,60)$ & 0.5 & 0.18 \\
\hline
\end{tabular}


Parameter values that are common among all entities in the simulation are shown in Table 8 .

Table 8. Model parameters in Topology 1.

\begin{tabular}{ccccccccc}
\hline Node & $\boldsymbol{T}$ & $\boldsymbol{r ( \% )}$ & $\tilde{\boldsymbol{i}}_{\boldsymbol{i}}$ & $\tilde{\boldsymbol{d}}_{\boldsymbol{i j}}$ & $\tilde{\boldsymbol{l}}_{\boldsymbol{i}}$ & $\tilde{\boldsymbol{p}}_{\boldsymbol{i}}$ & $\tilde{\boldsymbol{m}}_{\boldsymbol{i}}$ & $\tilde{\boldsymbol{d}}_{\boldsymbol{i b}}$ \\
\hline Value & 30 & 10 & 200 & 200 & 80 & 200 & 200 & 200 \\
\hline
\end{tabular}

The results of the simulation rely heavily on the values of relative cost coefficients. The cost coefficients determine the priorities for reaching the optimal state of entities. Therefore, due to our scenario regarding maximizing the cost of bank financing due to banking constraints, the cost coefficient of bank financing is chosen to be relatively high in comparison with other cost coefficients. Table 9 shows the simulated cost coefficient for each entity in the SC with Topology 1 . The cost coefficients of the available working capital are considered the second priority to be minimized in the cost function. This is accomplished by maximizing the amount of $I_{i}$. Additionally, we do not place a premium on minimizing the bank's debt value in this simulation.

Table 9. Relative cost coefficient values in Topology 1.

\begin{tabular}{ccccccc}
\hline Node & $g_{M}$ & $g_{Q}$ & $g_{L}$ & $g_{N}$ & $g_{I}$ & $g_{\text {Dib }}$ \\
\hline Value & 3 & 2 & 1 & 2 & 4 & 4 \\
\hline
\end{tabular}

The value of the inventory value cost coefficient $\left(g_{M i}\right)$ is chosen relative to as it could minimize the inventory level of each entity. Besides, to satisfy the positive definiteness of the input penalty matrix in LQR, we assign small values (2) for production in the network, which makes no difference in the final expected response as it is relatively low in comparison with other coefficients related to our goal.

Because of the simulation constraint, the simulated debt value to the bank and bank financing results are presented in Figure $2 a$, in which repetitive bank financing is avoided by entities due to the unnecessary cost of bank financing in comparison to profit cost. Moreover, various model assumptions, such as entity absolute profitability and the T-day payment duration, have a role in this pattern. As shown in the results, the entities may seek bank funding and tolerate its high expenses in the early days in order to increase their working capital. 

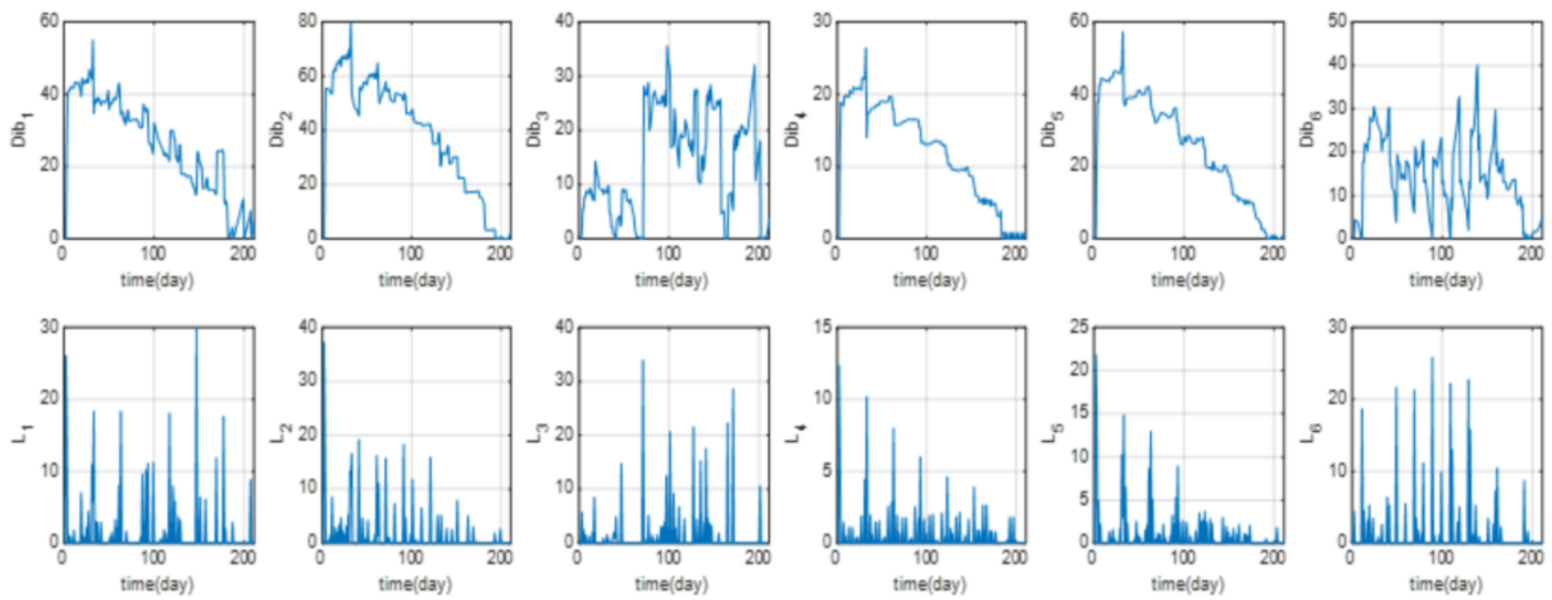

(a)
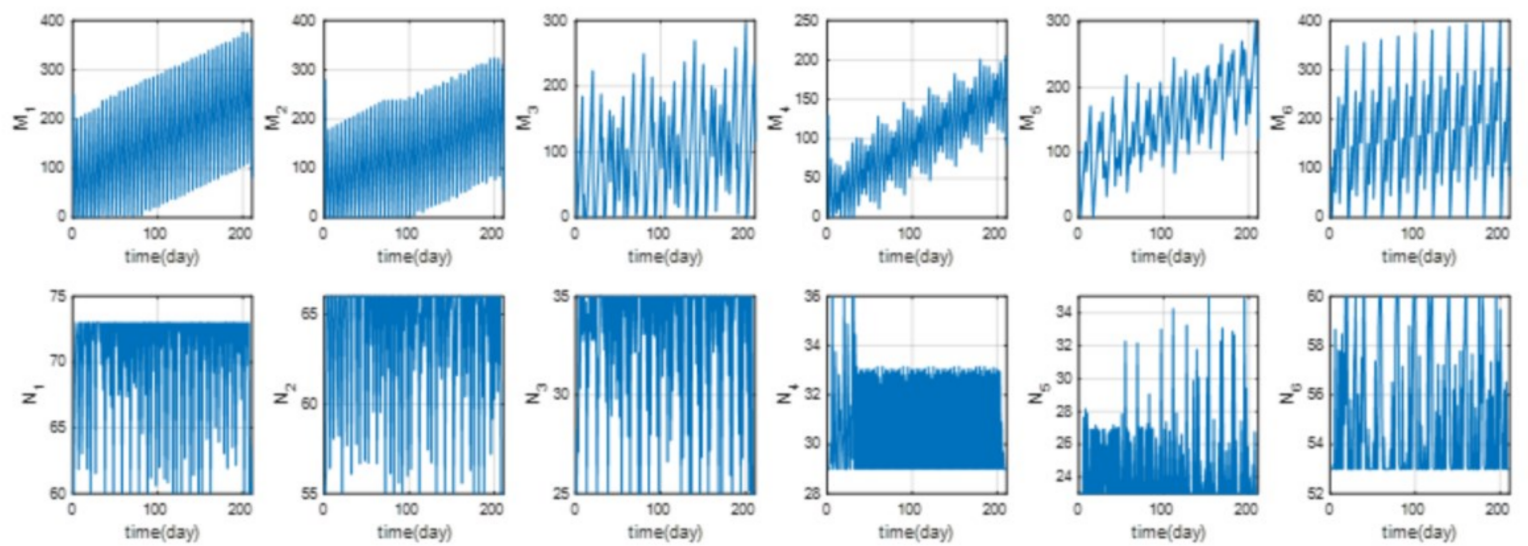

(b)
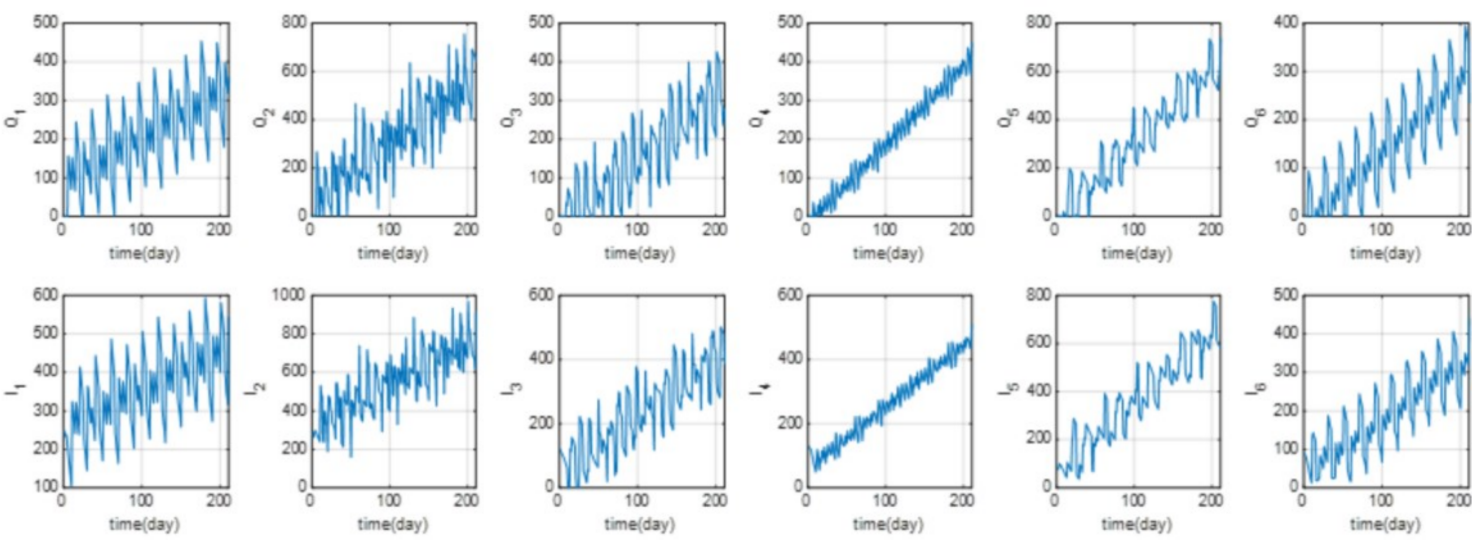

(c)

Figure 2. Results of simulation for Topology 1: (a) the results of simulated debt value to the bank (first row) and bank financing (second row) for each entity, (b) the results of simulated inventory level (first row) and production values (second row) for each entity, and (c) the results of simulated profit value (first row) and working capital (second row) for each entity.

Figure $2 \mathrm{~b}$ shows the planned production and inventory values. The behavior of inventory values follows the orders received by each entity, with the production optimally scheduled to minimize the inventory level in the planning horizon. 
We fixed the lag period for payment of received orders, $\left(k-k^{\prime}\right)$, to a constant value of 5 because we prefer to minimize indebtedness among entities. Figure $2 c$ depicts the working capital and profit behaviors among entities.

Since all entities run profitable operations, the working capital trajectory of entities plotted in Figure $2 \mathrm{c}$ shows a general uptrend in most cases. This trend is more significant for those entities that receive higher order amounts. It is worth mentioning that the marginal profits of nodes are equal within each layer due to the same values of fixed and variable costs, as shown in Table 7. According to Equation (2) and Figure 2c, when the working capital of each node approaches zero, if the entity could not create liquidity by selling any goods from inventory, the short-term financing occurs to achieve business continuity.

\subsection{Topology 2}

This topology is related to the SC of the Iranian pharmaceutical industry. Topology 2 is created using the actual financial statements of companies in this SC (Figure 3).

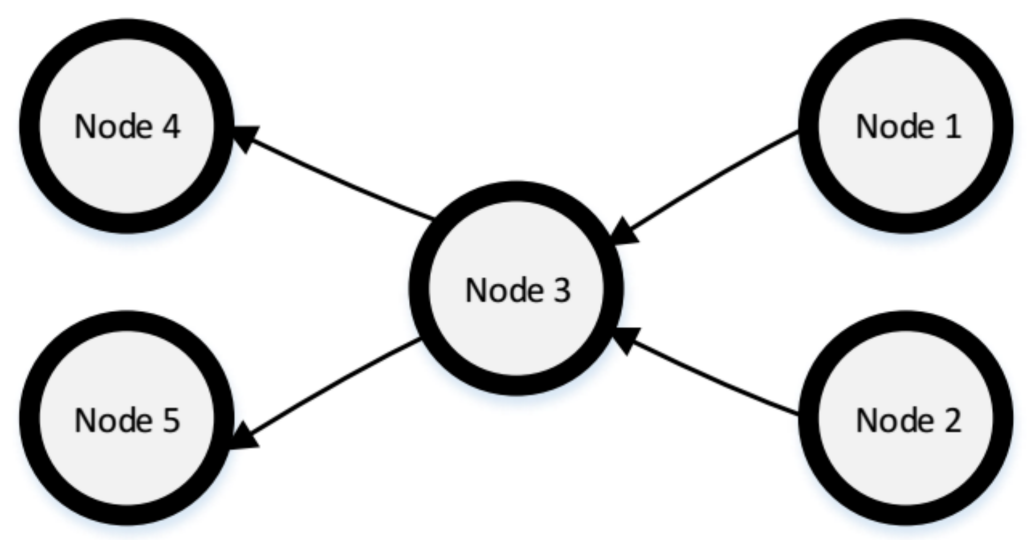

Figure 3. Topology 2 on a SC.

Tables of this topology, such as Topology 1, contain the following information. Table 10 summarizes the amount and frequency of orders sent to the suppliers by each node in tuples of the form (amount, frequency).

Table 10. Ordering behavior of nodes in Topology 2.

\begin{tabular}{cccccc}
\hline From/To & Node 1 & Node 2 & Node 3 & Node 4 & Node 5 \\
\hline Node 1 & - & - & $(90,743,7)$ & - & - \\
\hline Node 2 & - & - & $(24,748,7)$ & - & - \\
\hline Node 3 & - & - & - & $(81,643,30)$ & $(35,497,30)$ \\
\hline Node 4 & - & - & - & - & - \\
\hline
\end{tabular}

Orders received (by Nodes 1 and 2) and sent (by Nodes 4 and 5) to outside the network by nodes in the output and input layer are described in Table 11.

Table 11. Orders related to the outside of the network Topology 2.

\begin{tabular}{cc}
\hline Orders Description & (Amount, Frequency) \\
\hline Orders received by Node 1 & $(13,530,1)$ \\
\hline Orders received by Node 2 & $(3980,1)$ \\
\hline Orders sent by Node 5 & $(133,295,90)$ \\
\hline Orders sent by Node 6 & $(127,419,180)$ \\
\hline
\end{tabular}


The initial inventory value and fixed-parameter values specific to each entity are presented in Table 12. Fixed and variable costs are set to leave each entity a profit margin.

Table 12. Specific parameters of entities in Topology 2.

\begin{tabular}{cccccc}
\hline From/To & $\boldsymbol{M}_{\boldsymbol{i}}(\mathbf{O})$ & $\boldsymbol{P} \boldsymbol{p}_{\boldsymbol{i}}(\mathbf{\%})$ & $\left(\tilde{\boldsymbol{n}}_{\boldsymbol{i}}, \underline{\mathbf{n}}_{\boldsymbol{i}}\right)$ & $\boldsymbol{C}_{\boldsymbol{c} \boldsymbol{i}}$ & $\boldsymbol{C}_{\boldsymbol{v} \boldsymbol{i}}$ \\
\hline Node 1 & 14,000 & 15 & $(12,800,14,900)$ & 5 & 0.03 \\
\hline Node 2 & 4000 & 19 & $(3530,4400)$ & 17 & 0.1 \\
\hline Node 3 & 12,000 & 14 & $(13,000,19,000)$ & 20 & 10 \\
\hline Node 4 & 1000 & 18 & $(3100,4000)$ & 10 & 0.9 \\
\hline Node 5 & 1000 & 19 & $(1200,1600)$ & 0.12 \\
\hline
\end{tabular}

Parameter values that are common among all entities in the simulation are shown in Table 13.

Table 13. Model parameters in Topology 2.

\begin{tabular}{cccccc}
\hline Parameter & $\boldsymbol{T}$ & $\boldsymbol{r}(\boldsymbol{\%})$ & $\tilde{\boldsymbol{i}}_{\boldsymbol{i}}$ & $\tilde{\boldsymbol{l}}_{\boldsymbol{i}}$ & $\tilde{\boldsymbol{m}}_{\boldsymbol{i}}$ \\
\hline Amount & 30 & 10 & 200,000 & 100,000 & 50,000 \\
\hline
\end{tabular}

Table 14 shows the simulated cost coefficient for each entity in the SC with Topology 2.

Table 14. Relative cost coefficient values in Topology 2.

\begin{tabular}{ccccccc}
\hline Node & $g_{M}$ & $g_{Q}$ & $g_{L}$ & $g_{N}$ & $g_{I}$ & $g_{\text {Dib }}$ \\
\hline Value & 0.1 & 1 & 0.01 & 0.1 & 1 & 0.01 \\
\hline
\end{tabular}

The results of the simulation for Topology 2 are as follows.

The simulation results in Topology 2 in Figure 4 are similar to the results in Topology 1. The results of Topology 2 in Figure 4 a show that each entity is initially more willing to take a loan from the bank and over time, by increasing profitability, their desire to receive a loan decreases and the required working capital is provided through profits. Moreover, Figure $4 \mathrm{~b}$ show the upward trend of the production value until it reaches its maximum value in all nodes. In addition, the results in Figure $4 \mathrm{c}$ regarding the two variables of working capital and final profit show that with the passage of time and the activity of the company, these two variables have increased and the amount of short-term financing from the bank has decreased.

By simulating the aforementioned scenarios, each entity's ideal production, funding by banks, and debt repayment to upstream businesses are scheduled. We arrive at a globally optimal solution for the aggregate profitability of all entities using the convex QP optimization model presented in Equation (24). 

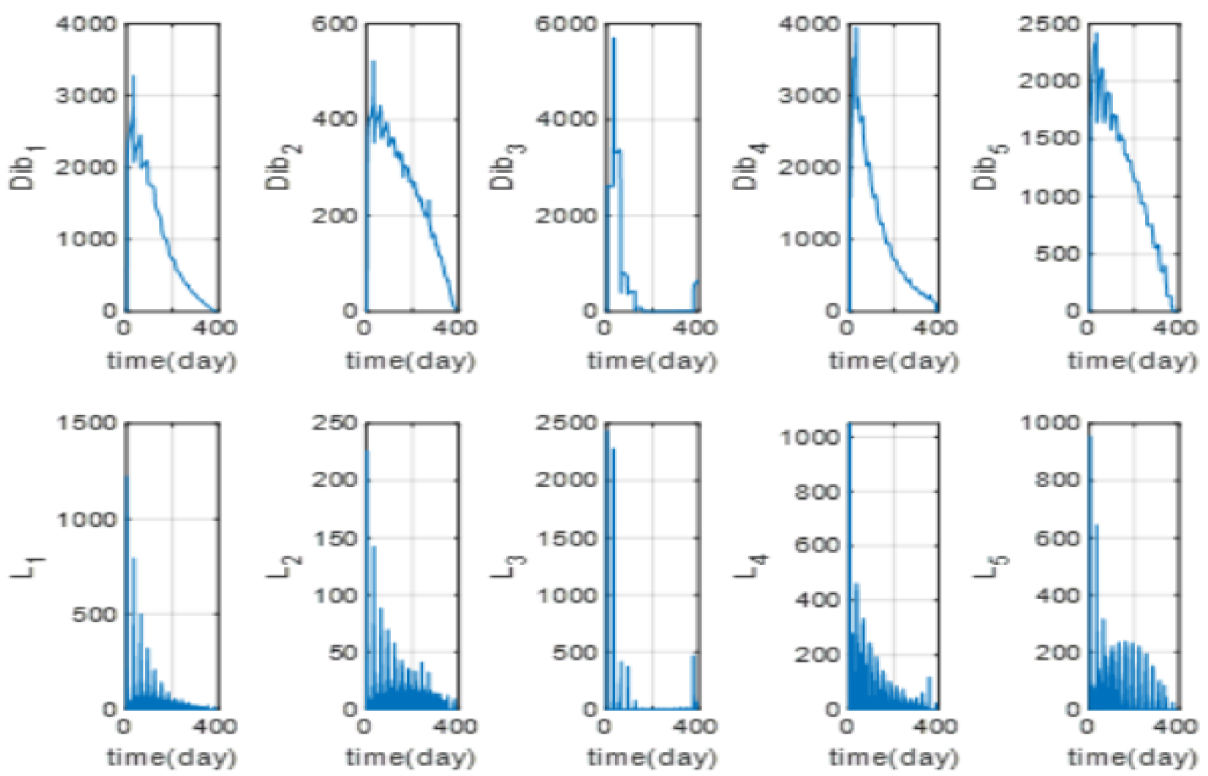

(a)
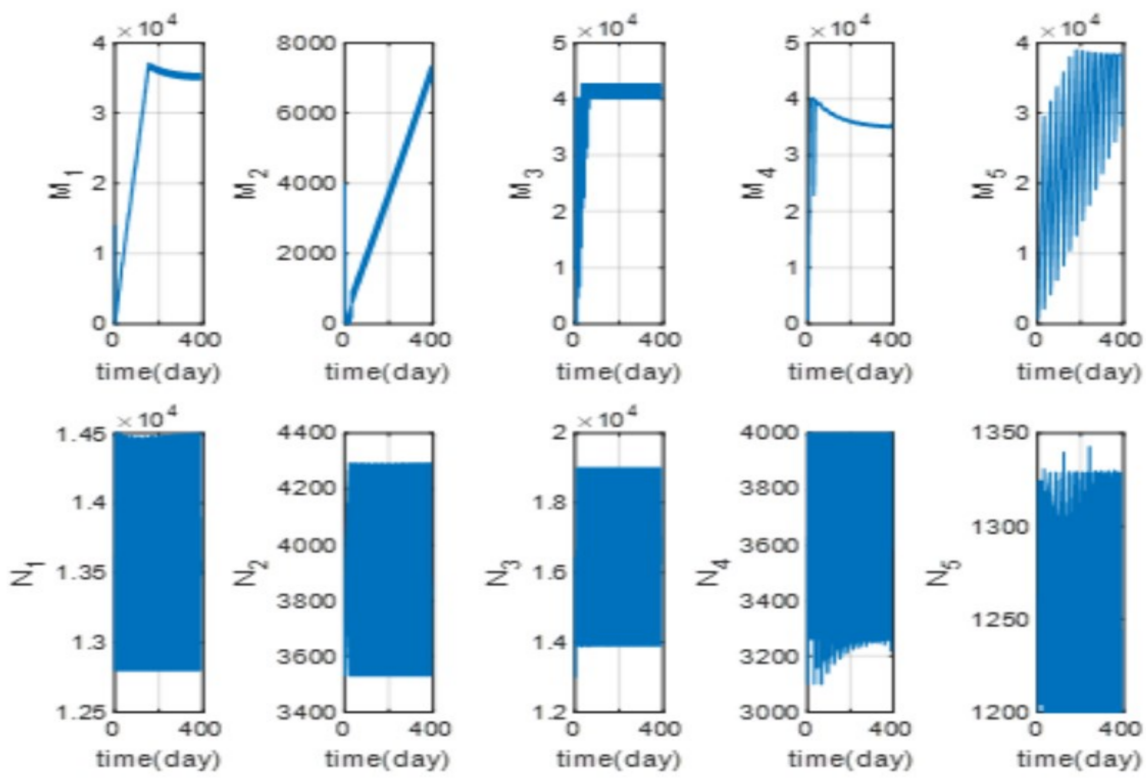

(b)

Figure 4. Cont. 

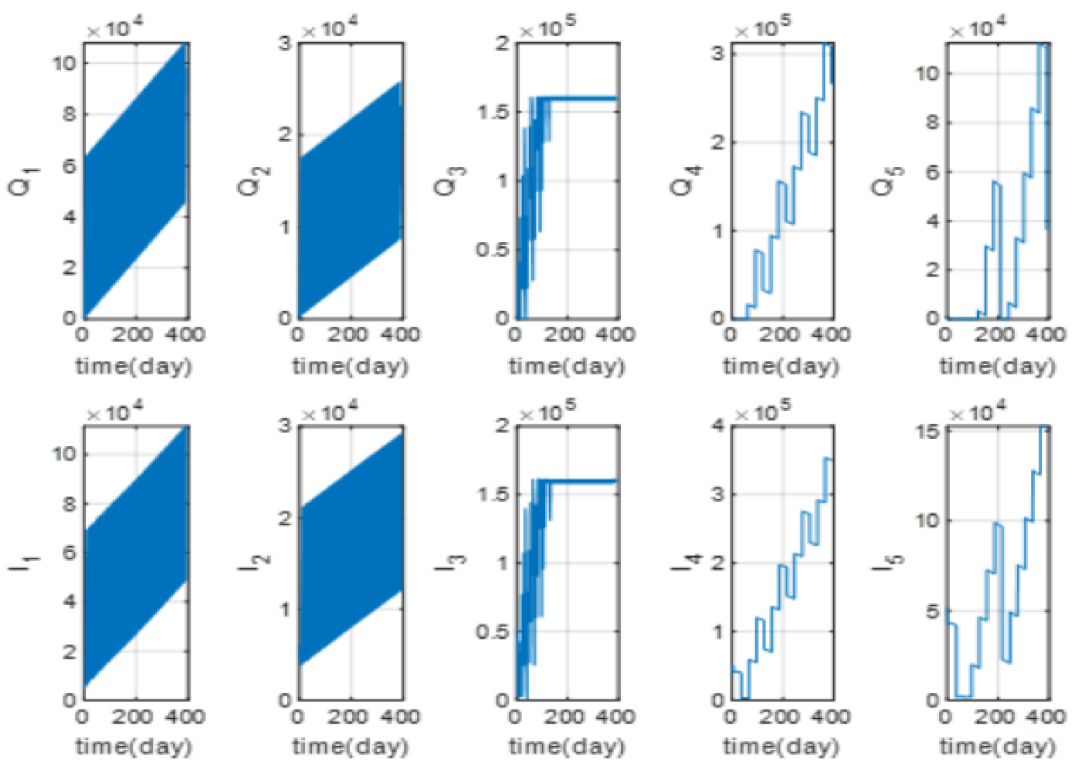

(c)

Figure 4. Results of simulation for Topology 2: (a) the results of simulated debt value to the bank (first row) and bank financing (second row) for each entity, (b) the results of simulated inventory level (first row) and production values (second row) for each entity, and (c) the results of simulated profit value (first row) and working capital (second row) for each entity.

\section{Conclusions}

This paper proposes a constrained finite-time LQR approach for determining an entity's optimal profit state in a SC. We focused on the optimization of the total profit in two different topologies of SC networks. Our model's foundation presupposes a noncompetitive environment in which the quantity and timing of orders are certain. The main issue in this framework is optimizing the total profit of the network by controlling external financing, internal financing, and inventory value. The problem is solved from a $\mathrm{SC}$ regulatory point of view, meaning the optimization is carried out to maximize profit of the entire SC.

Regarding the formulation of the model presented in this paper, variables are of two types. State variables are defined in the model to capture the dynamic behaviors of a system. Input variables are the means to control the model in our desired state, and they play the role of decision variables. Optimization is a relative concept in this framework. The chosen cost coefficients determine our priorities for reaching the optimal state of entities.

The results of simulated inventory and production values are shown in Figures $2 b$ and $4 b$. As is evident in both topology, the inventory value of entities presented in the first and last layers follows a clear repetitive pattern. This phenomenon happens because fixed order sizes are issued between every two entities in different layers throughout the simulation horizon. Although entities are allowed to postpone payment to upper entities by bearing the relative penalty cost, this behavior is not observed in the model due to the high priority of profit maximization and debt minimization.

The approach of dynamical systems in the solving of the model presented in this paper well answers the question of how the necessary changes on the control variables lead to determination of the appropriate values for the state variables and, ultimately, total profit maximization. According to the modeling and simulation results, which are clearly dependent on the entities' characteristics (network parameters), it is inferred that proper control of production variables and internal and external financing causes an uninterrupted production flow by receiving and sending appropriate input and output flows. This leads to a lack of stop production and creates critical points in the supply chain. It manages the 
supply chain's entities liquidity risk and maximizes total profit by using the potentials in the chain.

Based on the previous discussion, this helps policymakers who own the entire chain to plan for external financing and financial communication between members of the chain so that the production process is smooth and commensurate with the capacity of each entity and avoids the accumulation or a misplaced deficiency of production factors.

Since two issues, topology type and the characteristics of entities in the supply chain, have an important effect on the simulation results, sensitivity analysis on these cases can be the subject of future study in this topic.

Further development of this model can include considering demand uncertainty faced by first-layer SC members. Trade credit assumptions can also be added to this model in order to optimize the contracts regarding the payment delays of entities considering the whole SC. Risk-free investment opportunities and inventory costs could also be added to the model.

Author Contributions: Conceptualization, M.A.; Investigation, M.A.R.; Methodology, M.A.R.; Software, M.A.; Supervision, M.M.S. All authors have read and agreed to the published version of the manuscript.

Funding: This research received no external funding.

Institutional Review Board Statement: Not applicable.

Informed Consent Statement: Not applicable.

Data Availability Statement: Not applicable.

Conflicts of Interest: The authors declare no conflict of interest.

\section{References}

1. Harrison, A.; New, C. The role of coherent supply chain strategy and performance management in achieving competitive advantage: An international survey. J. Oper. Res. Soc. 2002, 53, 263-271. [CrossRef]

2. $\quad$ Mentzer, J.T.; DeWitt, W.; Keebler, J.S.; Min, S.; Nix, N.W.; Smith, C.D.; Zacharia, Z.G. Defining supply chain management. J. Bus. Logist. 2001, 22, 257-275. [CrossRef]

3. Popa, V. The financial supply chain management: A new solution for supply chain resilience. Amfiteatru Econ. J. 2013, 15, 140-153.

4. More, D.; Basu, P. Challenges of supply chain finance. Bus. Process Manag. J. 2013, 19, 624-647. [CrossRef]

5. Pfohl, H.C.; Gomm, M. Supply chain finance: Optimizing financial flows in supply chains. Logist. Res. 2009, 1, 149-161. [CrossRef]

6. Simatupang, T.M.; Sridharan, R. An integrative framework for supply chain collaboration. Int. J. Logist. Manag. 2005, 16, 257-274. [CrossRef]

7. Caldentey, R.; Chen, X. The role of financial services in procurement contracts. In The Handbook of Integrated Risk Management in Global Supply Chains; Kouvelis, P., Dong, L., Boyabatli, O., Li, R., Eds.; John Wiley \& Sons, Inc.: Hoboken, NJ, USA, 2009; pp. 289-326.

8. Wuttke, D.A.; Blome, C.; Henke, M. Focusing the financial flow of supply chains: An empirical investigation of financial supply chain management. Int. J. Prod. Econ. 2013, 145, 773-789. [CrossRef]

9. Liebl, J.; Hartmann, E.; Feisel, E.; Ellinger, A. Reverse factoring in the supply chain: Objectives, antecedents and implementation barriers. Int. J. Phys. Distrib. Logist. Manag. 2016, 46, 393-413. [CrossRef]

10. Chakuu, S.; Masi, D.; Godsell, J. Exploring the relationship between mechanisms, actors and instruments in supply chain finance: A systematic literature review. Int. J. Prod. Econ. 2019, 216, 35-53. [CrossRef]

11. Hofmann, E.; Belin, O. Supply Chain Finance Solutions; Springer: Berlin/Heidelberg, Germany, 2011.

12. Monto, S. Towards Inter-Organizational Working Capital Management; Lappeenranta University of Technology: Lappeenranta, Finland, 2013.

13. Kouvelis, P.; Zhao, W. Supply chain contract design under financial constraints and bankruptcy costs. Manag. Sci. 2016, 62, 2341-2357. [CrossRef]

14. Yan, N.; Sun, B.; Zhang, H.; Liu, C. A partial credit guarantee contract in a capital-constrained supply chain: Financing equilibrium and coordinating strategy. Int. J. Prod. Econ. 2016, 173, 122-133. [CrossRef]

15. Yang, H.; Zhuo, W.; Shao, L.; Talluri, S. Mean-variance analysis of wholesale price contracts with a capital-constrained retailer: Trade credit financing vs. bank credit financing. Eur. J. Oper. Res. 2021, 294, 525-542. [CrossRef]

16. Jing, B.; Seidmann, A. Finance sourcing in a supply chain. Decis. Support Syst. 2014, 58, 15-20. [CrossRef]

17. Richards, V.D.; Laughlin, E.J. A cash conversion cycle approach to liquidity analysis. Financial Manag. 1980, 9, 32-38. [CrossRef] 
18. Deloof, M. Does working capital management affect profitability of belgian firms? J. Bus. Finance Account. 2003, 30, 573-588. [CrossRef]

19. Hofmann, E.; Kotzab, H. A supply chain-oriented approach of working capital management. J. Bus. Logist. 2010, 31, 305-330. [CrossRef]

20. Gelsomino, L.M.; de Boer, R.; Steeman, M.; Perego, A. An optimization strategy for concurrent supply chain finance schemes J. Purch. Supply Manag. 2019, 25, 185-196. [CrossRef]

21. Margolis, J.T.; Sullivan, K.M.; Mason, S.J.; Magagnotti, M. A multiobjective optimization model for designing resilient supply chain networks. Int. J. Prod. Econ. 2018, 204, 174-185. [CrossRef]

22. Yan, N.; He, X.; Liu, Y. Financing the capital-constrained supply chain with loss aversion: Supplier finance vs. supplier investment. Omega 2019, 88, 162-178. [CrossRef]

23. Zenkevich, N.; Ivakina, A. Working capital optimization in supply chains. Corp. Finance 2018, 12, 29-42. [CrossRef]

24. Peng, J.; Zhou, Z. Working capital optimization in a supply chain perspective. Eur. J. Oper. Res. 2019, 277, 846-856. [CrossRef]

25. Rao, S.S. Engineering Optimization: Theory and Practice; John Wiley \& Sons: Hoboken, NJ, USA, 2019.

26. Trisna, T.; Marimin, M.; Arkeman, Y.; Sunarti, T. Multiobjective optimization for supply chain management problem: A literature review. Decis. Sci. Lett. 2016, 5, 283-316. [CrossRef]

27. Oliveira, J.; Jin, M.; Lima, R.S.; Kobza, J.E.; Montevechi, J.A.B. The role of simulation and optimization methods in supply chain risk management: Performance and review standpoints. Simul. Model. Pract. Theory 2019, 92, 17-44. [CrossRef]

28. Dantzig, G.B. Linear Programming and Extensions; Princeton University Press: Princeton, NJ, USA, 1998 ; Volume 48.

29. Taha, H.A. Operation Research An Introduction; Prentice-Hall Inc.: Hoboken, NJ, USA, 2008.

30. Sahay, N.; Ierapetritou, M. Flexibility assessment and risk management in supply chains. AIChE J. 2015, 61, 4166-4178. [CrossRef]

31. Park, Y.B.; Kim, H.S. Simulation-based evolutionary algorithm approach for deriving the operational planning of global supply chains from the systematic risk management. Comput. Ind. 2016, 83, 68-77. [CrossRef]

32. Kirılmaz, O.; Erol, S. A proactive approach to supply chain risk management: Shifting orders among suppliers to mitigate the supply side risks. J. Purch. Supply Manag. 2017, 23, 54-65. [CrossRef]

33. Tabrizi, B.H.; Razmi, J. Introducing a mixed-integer non-linear fuzzy model for risk management in designing supply chain networks. J. Manuf. Syst. 2013, 32, 295-307. [CrossRef]

34. Applequist, G.; Pekny, J.; Reklaitis, G. Risk and uncertainty in managing chemical manufacturing supply chains. Comput. Chem. Eng. 2000, 24, 2211-2222. [CrossRef]

35. Carneiro, M.C.; Ribas, G.P.; Hamacher, S. Risk management in the oil supply chain: A CVaR approach. Ind. Eng. Chem. Res. 2010, 49, 3286-3294. [CrossRef]

36. Sodhi, M.S. Managing demand risk in tactical supply chain planning for a global consumer electronics company. Prod. Oper. Manag. 2005, 14, 69-79. [CrossRef]

37. Klibi, W.; Martel, A. Modeling approaches for the design of resilient supply networks under disruptions. Int. J. Prod. Econ. 2012, 135, 882-898. [CrossRef]

38. d'Amore, F.; Bezzo, F. Managing technology performance risk in the strategic design of biomass-based supply chains for energy in the transport sector. Energy 2017, 138, 563-574. [CrossRef]

39. Mostafaeipour, A.; Qolipour, M.; Eslami, H. Implementing fuzzy rank function model for a new supply chain risk management. J. Supercomput. 2017, 73, 3586-3602. [CrossRef]

40. Kabir, S.; Papadopoulos, Y. Applications of Bayesian networks and petri nets in safety, reliability, and risk assessments: A review Saf. Sci. 2019, 115, 154-175. [CrossRef]

41. Tuncel, G.; Alpan, G. Risk assessment and management for supply chain networks: A case study. Comput. Ind. 2010, 61, 250-259. [CrossRef]

42. Liu, L.; Liu, X.; Liu, G. The risk management of perishable supply chain based on colored Petri net modeling. Inf. Process. Agric. 2018, 5, 47-59.

43. Nair, A.; Vidal, J.M. Supply network topology and robustness against disruptions-an investigation using multi-agent model. Int. J. Prod. Res. 2011, 49, 1391-1404. [CrossRef]

44. Gao, G.X.; Fan, Z.P.; Fang, X.; Lim, Y.F. Optimal Stackelberg strategies for financing a supply chain through online peer-to-peer lending. Eur. J. Oper. Res. 2018, 267, 585-597. [CrossRef]

45. Reza-Gharehbagh, R.; Hafezalkotob, A.; Asian, S.; Makui, A.; Zhang, A.N. Peer-to-peer financing choice of sme entrepreneurs in the reemergence of supply chain localization. Int. Trans. Oper. Res. 2020, 27, 2534-2558. [CrossRef]

46. Cao, Y.; Zhang, J.H.; Ma, X.Y. Optimal financing and production decisions for a supply chain with buyer-backed purchase order financing contract. IEEE Access 2019, 7, 119384-119392. [CrossRef]

47. Li, H.; Mai, L.; Zhang, W.; Tian, X. Optimizing the credit term decisions in supply chain finance. J. Purch. Supply Manag. 2019, 25, 146-156. [CrossRef]

48. Zhong, Y.; Shu, J.; Xie, W.; Zhou, Y.W. Optimal trade credit and replenishment policies for supply chain network design. Omega 2018, 81, 26-37. [CrossRef]

49. Zhao, Z.; Chen, D.; Wang, L.; Han, C. Credit risk diffusion in supply chain finance: A complex networks perspective. Sustainability 2018, 10, 4608. [CrossRef] 
50. Hou, Y.; Wang, X.; Wu, Y.J.; He, P. How does the trust affect the topology of supply chain network and its resilience? An agent-based approach. Transp. Res. Part E Logist. Transp. Rev. 2018, 116, 229-241. [CrossRef]

51. Mizgier, K.J.; Wagner, S.M.; Holyst, J.A. Modeling defaults of companies in multi-stage supply chain networks. Int. J. Prod. Econ. 2012, 135, 14-23. [CrossRef]

52. Tang, C.S. Perspectives in supply chain risk management. Int. J. Prod. Econ. 2006, 103, 451-488. [CrossRef]

53. Sahin, F.; Robinson, E.P., Jr. Information sharing and coordination in make-to-order supply chains. J. Oper. Manag. 2005, 23, 579-598. [CrossRef]

54. Wu, T.; Huang, S.; Blackhurst, J.; Zhang, X.; Wang, S. Supply chain risk management: An agent-based simulation to study the impact of retail stock outs. IEEE Trans. Eng. Manag. 2012, 60, 676-686. [CrossRef]

55. Elleuch, H.; Hachicha, W.; Chabchoub, H. A combined approach for supply chain risk management: Description and application to a real hospital pharmaceutical case study. J. Risk Res. 2014, 17, 641-663. [CrossRef]

56. Forrester, J.W. Industrial dynamics. J. Oper. Res. Soc. 1997, 48, 1037-1041. [CrossRef]

57. Peng, M.; Peng, Y.; Chen, H. Post-seismic supply chain risk management: A system dynamics disruption analysis approach for inventory and logistics planning. Comput. Oper. Res. 2014, 42, 14-24. [CrossRef]

58. Liew, K.; Lee, C.K. Modeling and risk management in the offshore and marine industry supply chain. Int. J. Eng. Bus. Manag. 2012, 4, 2. [CrossRef]

59. Olson, D.L.; Wu, D. Risk management models for supply chain: A scenario analysis of outsourcing to china. Supply Chain Manag. Int. J. 2011, 16, 401-408. [CrossRef]

60. Bhosekar, A.; Ierapetritou, M. A framework for supply chain optimization for modular manufacturing with production feasibility analysis. Comput. Chem. Eng. 2021, 145, 107175. [CrossRef]

61. Kirk, D.E. Optimal Control Theory: An Introduction; Courier Corporation: Chelmsford, MA, USA, 2004.

62. Brogan, W.L. Modern Control Theory, 3rd ed.; Pearson Education: Bangalore, India, 1991.

63. Bemporad, A.; Morari, M.; Dua, V.; Pistikopoulos, E.N. The explicit linear quadratic regulator for constrained systems. Automatica 2002, 38, 3-20. [CrossRef]

64. Borrelli, F.; Bemporad, A.; Morari, M. Predictive Control for Linear and Hybrid Systems; Cambridge University Press: Cambridge, UK, 2017.

65. Xuan, P.; Lesser, V. Multi-agent policies: From centralized ones to decentralized ones. In Proceedings of the First International Joint Conference on Autonomous Agents and Multiagent Systems, Bologna, Italy, 15-19 July 2002; Volume 3, pp. 1098-1105.

66. Scokaert, P.O.; Rawlings, J.B. Constrained linear quadratic regulation. IEEE Trans. Autom. Control 1998, 43, 1163-1169. [CrossRef]

67. Lau, M.S.K.; Yue, S.P.; Ling, K.V.; Maciejowski, J.M. A comparison of interior point and active set methods for fpga implementation of model predictive control. In Proceedings of the 2009 European Control Conference (ECC), Budapest, Hungary, 23-26 August 2009; IEEE: Piscataway, NJ, USA, 2009; pp. 156-161. 